\title{
Avaliação de livros didáticos do Ensino Fundamental sobre conteúdos relacionados à preservação ambiental
}

\section{Evaluation of elementary school books with environmental conservation-related contents}

\author{
${ }^{1}$ Kelly Ferreira da Rocha kellyrocha.bio@gmail.com \\ ${ }^{2}$ Milena Nascimento Bento \\ ${ }^{3}$ Vinícius Peruzzi de Oliveira \\ ${ }^{4}$ Luciana Muguet Julio
}

\section{RESUMO}

Apesar dos perceptíveis avanços na concepção e implementação da Educação Ambiental no ensino brasileiro, o livro didático permanece ainda como um dos únicos instrumentos de veiculação deste tema na maioria das escolas. Nesse contexto, o presente trabalho teve o objetivo de analisar a abordagem do tema preservação ambiental em livros didáticos utilizados no ensino fundamental. A metodologia da pesquisa consistiu de análises quantitativas e qualitativas do tema em duas coleções de livros didáticos de ciências do ensino fundamental da rede pública de Volta Redonda/RJ. Os resultados mostraram que, embora haja uma preocupação sobre a temática ambiental, ainda se percebe deficiências nas estruturas dos livros didáticos avaliados, de forma que não são abordados assuntos referentes à preservação ambiental e inter-relação com meio ambiente.

Palavras-chave: Livros didáticos. Preservação ambiental. Análise qualitativa. Análise quantitativa.

\begin{abstract}
Despite the noticeable advances in the conception and implementation of Environmental Education in Brazilian education system, the schoolbook still remains as one of the only instruments to convey the theme in most schools. In this context, this study aimed to analyze how the textbooks used in primary education address the issue of environmental preservation. The study was carried out through quantitative and qualitative analysis of the topic in two collections of Science textbooks of elementary education in public schools in Volta Redonda/ RJ. The results showed that, although there is a concern with the environmental theme, there is still deficiencies in the evaluated textbook, so that subjects related to preservation and interrelation with the environment are not addressed.
\end{abstract}

Keywords: Schoolbooks. Environmental conservation. Qualitative and quantitative analysis.

\footnotetext{
Universidade Federal do Rio de Janeiro - Consórcio CEDERJ

Centro Universitário de Volta Redonda (UniFOA)

Universidade Federal do Rio de Janeiro - Departamento de Ecologia

Secretaria Municipal de Educação/RJ
} 


\section{INTRODUÇÃO}

Vivemos desde o início do século XXI uma crise ideológica, na qual existe a frequente ponderação a respeito do papel do ser humano em relação ao seu espaço ocupado no planeta e a respectiva qualidade de vida proposta (JACOBI, 2005). Assim, frequentemente é levantada a questão dos padrões do desenvolvimento socioeconômico com a utilização dos recursos naturais e os processos de degradação da natureza (VIOLANTE; SILVA, 2010). Nesse contexto, tem-se a Educação Ambiental (EA) como o meio dos quais o indivíduo e a coletividade constroem valores sociais, conhecimentos, habilidades, atitudes e competências voltadas para a conservação do meio ambiente, bem de uso comum do povo, essencial à sadia qualidade de vida e sua sustentabilidade (RODRIGUES, 2014). A inserção da questão ambiental em temas educacionais tem como propósito promover a análise da realidade socioambiental (DIAS, 2004), permitindo a compreensão do mundo natural e as consequências ecológicas em relação aos atos antropogênicos (HOANG; KATO 2016).

A partir da década de 60, e principalmente na década de 70, começaram a surgir conselhos e conferências internacionais em prol da conservação ambiental e da promoção da EA, o que ocasionou uma mudança de paradigma no que se refere ao uso dos recursos naturais, enfatizando a importância do desenvolvimento sustentável (Brasil, 2017). Especificamente em 1977, a Conferência Intergovernamental de Educação Ambiental, realizada em Tbilisi (Geórgia), definiu pela primeira vez os objetivos, princípios e estratégias da EA, princípios estes aplicados até os dias atuais (BARBIERI; SILVA 2011). A declaração de Tbilisi postula que a EA deve constituir-se em um processo contínuo e permanente, iniciado na pré-escola e continuando através de todas as fases do ensino formal e não-formal, valorizando dessa forma a inserção da educação ambiental em todos os níveis de ensino (CARVALHO, 2006).

No Brasil, no ano de 1999 foi publicada a lei que dispõe sobre a obrigatoriedade da EA em todos os níveis da educação (Lei 9.795/99), fazendo com que a questão ambiental passasse a ser objeto de constantes discussões no meio acadêmico e social (LIMA, 2004). Neste contexto, os Parâmetros Curriculares Nacionais (PCNs) determinam a cargo das escolas e do professor o papel de utilizar a Educação Ambiental com finalidade de aumentar a participação efetiva e consciente da sociedade (RODRIGUES, 2001). Dessa forma, questões ambientais foram inseridas em dois momentos nos PCNs, presente no volume 4, sobre as Ciências Naturais, sendo um dos objetivos desse conteúdo fazer o aluno compreender a natureza como um todo dinâmico, sendo o ser humano parte integrante e agente de transformações do mundo em que vive. Também presente como um tema transversal, no volume 9.1, permitindo que a EA seja trabalhada de forma transversal nas escolas, abordando os aspectos de interação e contextualização com ações cotidianas em diversos campos do conhecimento (SANTOS; COSTA 2013).

Entretanto, apesar de todas essas recomendações, os próprios PCNs ainda reiteram o pouco desenvolvimento da EA na educação brasileira (BRASIL, 2017c, p.182):

"É necessário ainda ressaltar que, embora recomendada por todas as conferências internacionais, exigida pela Constituição e declarada como prioritária por todas as instâncias de poder, a Educação Ambiental está longe de ser uma atividade tranquilamente aceita e desenvolvida, porque ela implica mudanças profundas e nada inócuas. Ao contrário, quando bem realizada, a Educação Ambiental leva a mudanças de comportamento pessoal e a atitudes e valores de cidadania que podem ter fortes consequências sociais. ”

Atualmente, percebe-se uma preocupação na inserção dos conceitos de meio ambiente nos livros didáticos, no qual se pode destacar o trabalho de Marpica e Logarezzi (2010), cujo o objetivo foi fazer o levantamento das pesquisas realizadas envolvendo livro didático e educação ambiental. A percepção da carência da temática ambiental nos livros didáticos também foi previamente discutida por Soares e Novicki (2005), onde foi citada a valorização da ciência como causa do déficit de conteúdos no material didático escolares. Recentemente, Suleiman e Zancul (2012) discutiram as visões restritas que os livros didáticos apresentam acerca dos conteúdos 
ambientais, proporcionando poucos questionamentos sobre os temas tratados, e ressaltando que os temas relacionados ao meio ambiente, na maioria das vezes, refletem poucos aspectos de uma EA crítica, privilegiando a aquisição de conceitos científicos, sem abranger a totalidade dos processos que levam à degradação ambiental e à redução da qualidade de vida dos seres humanos e demais seres vivos.

Nesse contexto, embora exista uma gama de trabalhos associados à EA, ainda se percebe uma necessidade de informação acerca do tema em livros didáticos de ciências e biologia do ensino fundamental. Observando esta questão, o presente trabalho foi desenvolvido objetivando analisar duas coleções de livros didáticos de ciências do ensino fundamental, utilizadas no município de Volta Redonda/ RJ, acerca do tema preservação e conscientização ambiental.

\section{METODOLOGIA}

O presente trabalho utilizou métodos de avaliações qualitativas e quantitativas dos temas de meio ambiente em duas coleções de livros didáticos, utilizados no ensino fundamental no ano letivo de 2013 em três escolas da rede pública municipal de Volta Redonda, estado do Rio de Janeiro (Tabela 1). A coleção Ciências de Fernando Gewandsznajder foi utilizada no colégio José Botelho de Athayde e no CIEP 295 Prof ${ }^{a}$ Glória Roussin Guedes Pinto, e a coleção Ciências Naturais de Olga Santana e Anibal Fonseca foi utilizada na Escola Municipal Dr. João Pio de Abreu.

Tabela 1: Livros didáticos do ensino fundamental adotados pelas escolas do município de Volta Redonda, RJ, no ano letivo de 2013.

\begin{tabular}{|c|c|c|c|c|c|c|}
\hline Título & Autor (es) & Editora & Edição & $\begin{array}{c}\text { Ano } \\
\text { escolar }\end{array}$ & Livro & Páginas \\
\hline \multirow{4}{*}{ Ciências - O planeta Terra } & \multirow{4}{*}{$\begin{array}{c}\text { Fernando } \\
\text { Gewandsznajder }\end{array}$} & \multirow{4}{*}{ Ática } & \multirow{4}{*}{$3^{a}$ edição } & $6^{\circ}$ ano & 1 & 232 \\
\hline & & & & $7^{\circ}$ ano & 2 & 272 \\
\hline & & & & $8^{\circ}$ ano & 3 & 248 \\
\hline & & & & $9^{\circ}$ ano & 4 & 272 \\
\hline \multirow{4}{*}{ Ciências Naturais } & \multirow{4}{*}{$\begin{array}{l}\text { Olga Santana } \\
\text { Anibal Fonseca }\end{array}$} & \multirow{4}{*}{ Saraiva } & \multirow{4}{*}{$3^{a}$ edição } & $6^{\circ}$ ano & 5 & 320 \\
\hline & & & & $7^{\circ}$ ano & 6 & 320 \\
\hline & & & & $8^{\circ}$ ano & 7 & 319 \\
\hline & & & & $9^{\circ}$ ano & 8 & 336 \\
\hline
\end{tabular}

Fonte: próprio autor.

\section{1 Avaliações quantitativas}

As avaliações quantitativas referiram-se aos números de trechos/tópicos com ocorrências que o tema preservação e consciência ambiental foi abordado nos livros e a porcentagem da cobertura do conteúdo na página em que o tema ocorre.

Para a estimativa da área ocupada pelo tema em cada página do livro em que o tema ocorreu, utilizou-se uma adaptação do método de amostragem por porcentagem de cobertura, proposto por Dethier et al. (1993). Para isso, foi utilizada uma folha plástica transparente, segmentada em partes iguais, de forma que fosse possível observar 16 quadrados (cada quadrado corresponde a 6,25\% de cobertura da página avaliada). 


\section{2 Avaliações qualitativas}

Esta análise considerou a proposta de reflexão sobre a atual situação do meio ambiente no tocante a presença de EA na conscientização dos discentes. Baseado em Carvalho (2002), foram estabelecidos três critérios de avaliação:

\section{$1^{\circ}$ critério -Presença do tema preservação ambiental}

Foi observado, em cada livro avaliado, a ocorrência de assuntos relacionados à preservação e consciência ambiental.

\section{$2^{\circ}$ critério - Contextualização do tema apresentado}

Quando algum conteúdo de preservação e consciência ambiental esteve presente, foi verificado se o mesmo foi abordado de forma transversal, em diferentes assuntos do livro, ou em capítulos específicos.

\section{$3^{\circ}$ critério - Nível de aprofundamento do tema}

Também foram estabelecidos dois níveis qualitativos (superficial e aprofundada) para avaliação da intensidade de abordagem do tema preservação e consciência ambiental:

(i) Superficial - indicando apenas ações básicas (ex: “não devemos jogar lixo no chão” ou “devemos reciclar o lixo”), sem abordar o cerne da questão;

(ii) Aprofundada - indicando presença de reflexão e discussão da problemática abordada (ex: “como se chegou a atual situação?” ou “quais atitudes devemos tomar como cidadãos conscientes?”).

Figura 1: Fluxograma da metodologia utilizada para avaliação do livro didático.

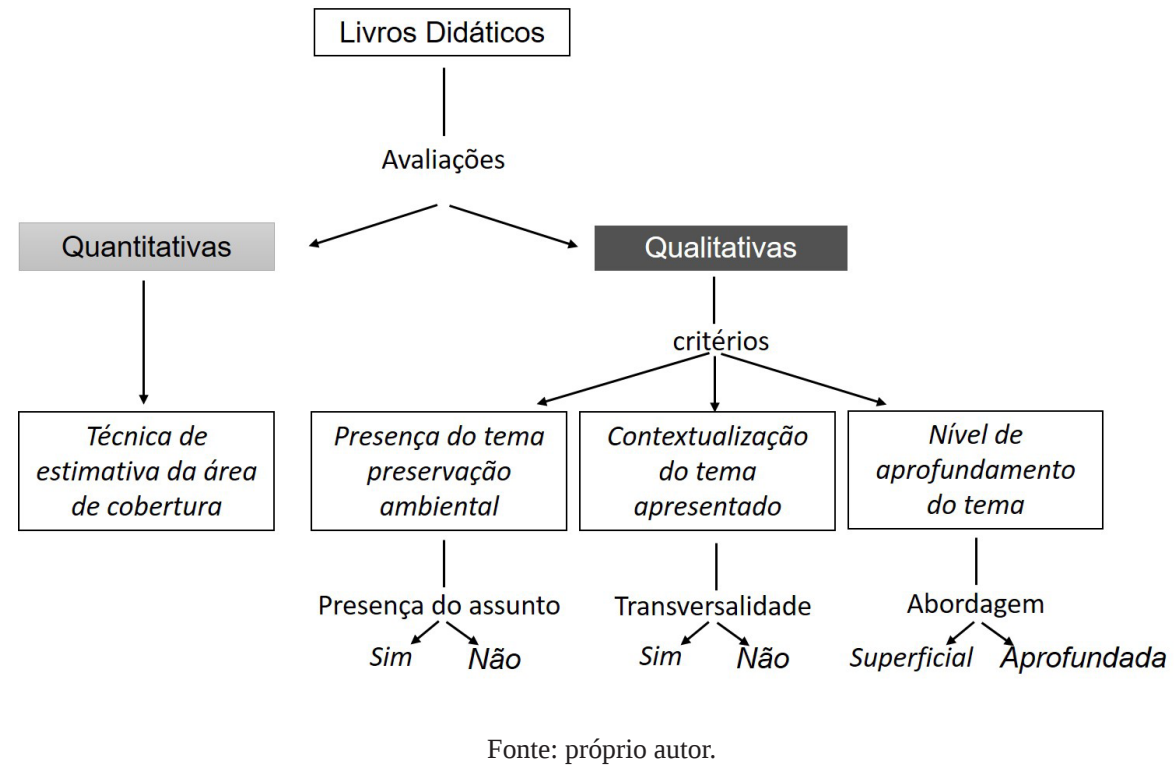




\section{RESULTADOS E DISCUSSÃO}

\section{1 Análise quantitativa do conteúdo sobre Educação Ambiental}

O livro 1, teve a maior quantidade de citações acerca do tema preservação e consciência ambiental (14 vezes). No livro 2, foram registadas cinco ocorrências do tema, e nos livros 5 e 7 ocorreram quatro vezes. Os demais livros não apresentaram inserções temáticas a respeito da preservação ambiental. De certo modo, todos os conteúdos citados estiveram associados às mudanças antropogênicas, no qual grande parte esteve ligada às consequências do desmatamento. Embora seja conhecida a importância do desenvolvimento da conscientização e preservação ambiental, foi notória baixa frequência com que este assunto foi abordado nos livros didáticos diante da importância que se deve dar para tal e ao estabelecido pelo Programa de Livro Didático.

Nesse contexto, sabe-se que as questões ambientais vêm sendo discutidas atualmente devido às grandes mudanças que estão ocorrendo no nosso planeta como, por exemplo, as alterações climáticas e os altos níveis globais de desmatamento. Em geral, a baixa frequência de ocorrências está associada à distância entre o conhecimento acadêmico e o conhecimento escolar e, as incertezas que cercam os debates sobre as mudanças globais (LIMA; LAYRARGUES 2014). Além disso, Ribeiro (2006), ressaltou que os temas ambientais estão sendo abordados nos livros didáticos de modo pontual, e destaca que é incomum orientações de atuação, e quando propostas, referem-se a atitudes específicas e individuais de conservação de componentes da natureza. Bezerra (2002) também apontou a baixa quantidade de conteúdo ambiental nos livros didáticos analisados. Assim, percebe-se que ainda existe uma carência de informações nos livros didáticos, o que denota a necessidade da uma inserção conteudista em relação ao meio ambiente.

\section{2 Porcentagem de cobertura}

As 27 citações do tema preservação e consciência ambiental estiveram presentes em apenas 75 páginas, em um total de 2319 páginas (3,7\%). Dessas 75 páginas, em 51 delas o tema foi abordado em 100\% da cobertura da página, em quatro páginas o tema ocupa 75\% da página, seis páginas apresentam o tema em 50\% da página e em 14 o tema aparece em $25 \%$ da área de cobertura (figura 2).

Figura 2: Número de páginas e porcentagem de cobertura do tema preservação e consciência ambiental, em livros utilizados no município de Volta Redonda/ RJ em 2013.

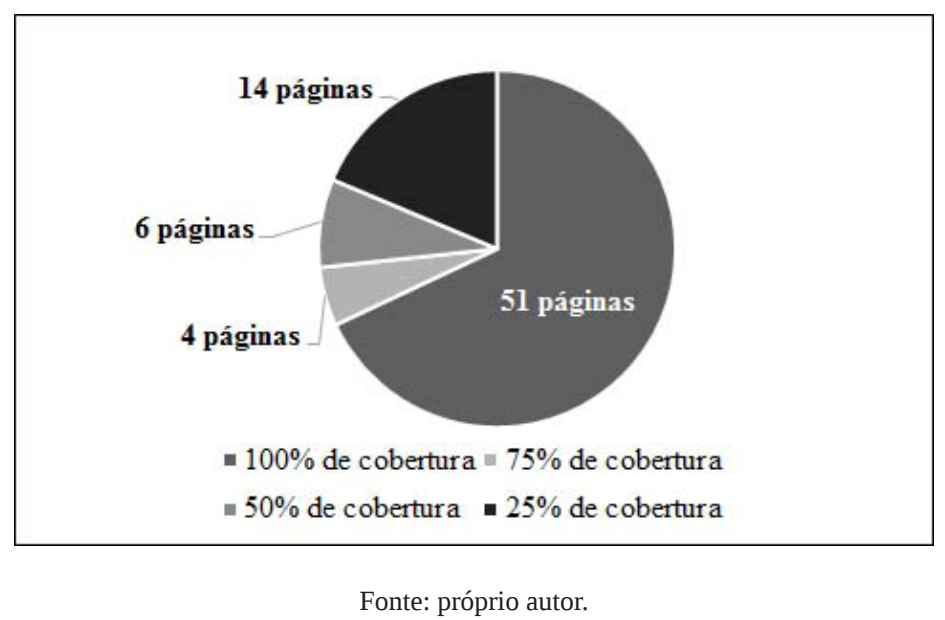

Pode-se perceber que os números de citações no livro não correspondem à proporção de páginas destinadas ao tema. No livro 1, o tema foi abordado em 26 páginas, com 10 páginas registando 100\% de cobertura relacionado ao assunto (Tabela 2). No livro 2, houve um maior número de páginas com 25\% de cobertura acerca 
do tema. No livro 5, o tema foi abordado em 31 páginas, na qual apenas uma página apresentava $75 \%$ de cobertura e 30 páginas com 100\% de cobertura. No livro 7, foi o que apresentou menor número de páginas (8), o tema ocupando 100\% de cobertura em 5 páginas.

Tabela 2: Número de páginas que abordaram o tema preservação e consciência ambiental e as respectivas porcentagens de cobertura nos livros didáticos utilizados no município de Volta de Radonda/ RJ em 2013.

\begin{tabular}{ccccc}
\hline Porcentagem de Cobertura & Livro 1 & Livro 2 & Livro 5 & Livro 7 \\
\hline $100 \%$ & 10 & 0 & 30 & 5 \\
$75 \%$ & 6 & 4 & 1 & 0 \\
$50 \%$ & 4 & 1 & 0 & 1 \\
$25 \%$ & 7 & 5 & 0 & 2 \\
\hline
\end{tabular}

Em geral, a maior porcentagem de cobertura esteve associada à presença de ilustrações e propostas de atividades. De certo modo, a presença de ilustrações ajuda na construção cognitiva do tema abordado. Contudo, em estudo realizado por Mendonça Filho e Tomazello (2002) foi registrado que imagens de ecossistemas em livros didáticos de ciências do Ensino Fundamental, referentes processos de educação ambiental, e concluíram que as imagens, em geral, induzem a interpretações desarmônicas entre o ambiente natural e as atividades antropogênicas. Levando em consideração o estudo desses autores percebe-se que o uso de figuras de fácil entendimento, é fundamental para o crescimento cognitivo do estudante. Nesse contexto, a presença de quadros explicativos, ilustrações e esquemas auxiliam o aprendizado. Além disso, essas ferramentas podem auxiliar os discentes na compreensão da influência direta do homem sobre o meio ambiente, e a importância de uma postura consciente.

\section{3 Análise qualitativa do conteúdo sobre Educação Ambiental}

Avaliando o contexto na qual a EA se insere foi possível perceber a abordagem do tema em diversos conteúdos como, classificação dos seres vivos, ecologia, a dinâmica da vida na Terra e poluição. Fato que denota a transversalidade na área de meio ambiente incluindo os ciclos da natureza, sociedade e meio ambiente, manejo e conservação ambiental como sugerido pelos parâmetros curriculares nacionais.

O livro 1 abordou de forma aprofundada a EA, no qual o tema "preservação ambiental" foi reportado 14 vezes, explicitando as atitudes antropogênicas que levaram e levam a degradação do meio ambiente, como queimadas, desmatamento, emissões de poluentes, produção excessiva de lixo, consumismo exacerbado dos recursos naturais, uso dos recursos naturais renováveis e não-renováveis, entre outros. O livro também menciona as consequências dessas atitudes antrópicas, como, a extinção de espécies, a escassez de recursos naturais, como a escassez de água, a transmissão de doenças, deslizamentos de terra, o desequilíbrio na cadeia alimentar e consequentemente de toda natureza. Além disso, há destaque para a dedicação exclusiva de um capítulo voltado para o assunto "lixo", no qual são abordadas as causas, consequências, e ações que devem ser tomadas para minimizar a agressão que o lixo causa ao meio ambiente, ensina técnicas de compostagem, separação e destinação adequada do lixo, e reciclagem. Deixando evidente o conceito de 3 R's (reutilizar, reciclar e reduzir), proposto por Rizzo et al. (2007).

No livro 2 o tema preservação ambiental foi trabalhado cinco vezes. Em todos esses momentos o tema esteve vinculado à extinção de espécies ou à inserção de espécies exóticas causando desequilíbrio ambiental. O livro mostra as consequências das queimadas, desmatamentos e métodos de extração de recursos naturais, como coleta de produtos vegetais, mineração e garimpo, e a inundação de grandes áreas para construção de represas de usinas hidrelétricas. Contudo, não enfatiza quais devem ser as atitudes que devem ser tomadas por nós a respeito desta situação, apenas diz que o governo deve combater a biopirataria, saída ilegal de organismos do país, 
e investir em pesquisas de fauna e flora. Portanto, a avaliação do Livro 2 levou a classifica-lo como superficial em relação ao tema.

O livro 5 é que apresenta maior número de páginas sobre o tema meio ambiente. Este livro também possui um capítulo destinado exclusivamente na abordagem dos aspectos ambientais em torno da produção de lixo, onde são expostas as ideias de transmissão de doenças, além de contaminação do solo e das águas. O livro também aborda o tempo que os resíduos sólidos levam para se decompor. Além disso, o capítulo aponta a importância dos 3 R's, dando exemplos de aproveitamento de materiais usados para fabricação de outros. O livro também ressalta que a responsabilidade ambiental não é de cunho exclusivo governo, uma vez que problema que afeta todos os indivíduos, e aborda a preservação mencionando aspectos sobre os recursos naturais renováveis e não renováveis. Assim, os conteúdos abordados foram classificados como aprofundados.

No Livro 7 a preservação ambiental está diretamente ligada à ameaça aos ecossistemas, abordando o desmatamento, as queimadas, a caça ilegal, mineração, biopirataria, derramamento de petróleo, produção de lixo e esgoto e emissões de gás. O livro abrange também os malefícios à saúde e o aquecimento global, devido a degradação do ambiente, e ressalta a importância do cuidado global, havendo a necessidade da preservação conjunta de todos os ecossistemas e biomas. Embora sejam poucas as citações (4) e os números de páginas utilizados (7), percebe-se propostas de reflexões complexas, o que denota o aprofundamento do conteúdo.

Em síntese, os Livros 1 e 5 possuem como proposta a inserção do tema Meio ambiente, com seus conteúdos voltados para os ecossistemas, a água, o solo. Estes assuntos estão diretamente relacionados a Educação Ambiental, o que facilita a abordagem da preservação ambiental. O Livro 2, está baseado, principalmente, na taxonomia dos seres vivos e os reinos animais, também permite a inserção da educação ambiental. Porém, os livros didáticos do $8^{\circ}$ e $9^{\circ}$ ano, por possuírem abordagens de conteúdos sobre o corpo humano e introdução a física e química, respectivamente, pouco permeiam o tema a preservação ambiental.

Seguindo os critérios estabelecidos nesse trabalho, pôde-se perceber que apenas o livro 1 e o livro 2, da coleção Ciências de Fernando Gewandsznajder, juntamente com o livro 5 e o livro 7 da coleção Ciências Naturais de Olga Santana e Anibal Fonseca, apresentam abordagens efetiva acerca do tema preservação e consciência ambiental.

\section{CONSIDERAÇÕES FINAIS}

A pesquisa permitiu concluir que dentre os livros analisados, os que abordam preservação e consciência ambiental apresentam conteúdos adequados, porém fica evidente que a frequência de abordagem do tema preservação ambiental nos livros didáticos ainda é muito baixa diante da proposta de transversalização do tema, como proposto pelos parâmetros curriculares nacionais. Neste sentido, percebe-se que os livros didáticos ainda carecem de informações que contribuam para formação de um cidadão cooperativo e ativo. 


\section{REFERÊNCIAS}

BARBIERI, J. C.; Silva, D. Desenvolvimento sustentável e educação ambiental: uma trajetória comum com muitos desafios. RAM, Rev. Adm. Mackenzie, V. 12, N. 3, 2011.

BEZERRA, O. S. Temáticas ambientais nos livros didáticos, 2003. Disponível em: < http://servicos.capes.gov. br/capesdw/resumo.html?idtese=200313124001015038P5>; Acesso em: 27 abr. 2008.

Brasil 2017 a. 7. Um pouco da História da Educação Ambiental. http://portal.mec.gov.br/secad/arquivos/pdf/ educacaoambiental/historia.pdf

Brasil 2017b. Um pouco da História da Educação Ambiental. http://portal.mec.gov.br/secad/arquivos/pdf/ educacaoambiental/historia.pdf

Brasil 2017c. Parâmetros curriculares nacionais: apresentação dos temas transversais, ética / Secretaria de Educação Fundamental. Brasília: MEC/SEF.

BRASÍLIA. Vamos cuidar do Brasil: conceitos e práticas em educação ambiental na escola / [Coordenação: Soraia Silva de Mello, Rachel Trajber]. - Ministério da Educação, Coordenação Geral de Educação Ambiental: Ministério do Meio Ambiente, Departamento de Educação Ambiental: UNESCO, 2007.

CARVALHO, I. C. Educação, Natureza e Cultura: ou sobre o destino das latas. IN: Zarzkzevski, S.; Barcelos, V. (Orgs) Educação Ambiental E Compromisso Social: Pensamentos e Ações. Erexim, Edifapes, 2004. Pp 163174. Disponível em: <http://www.ambiente.gov.ar/infotecaea/descargas/carvhalo03.pdf $>$. Acesso em: 18/06/13.

CARVALHO, I. C. M. Educação ambiental: a formação do sujeito ecológico. 2.ed. São Paulo: Cortez, 2006.

Dethier, M. N.; Graham, E. S.; Cohen, S.; Mear, L. M. Visual versus random-point percent cover estimations: 'objective' is not always better. Mar. Ecol. Prog. Ser. Vol. 96: 93-100.1993 .

DIAS, G. F. Ecopercepção: um resumo didático dos desafios socioambientais. São Paulo: Ed. Gaia, p 23, 2004

HOANG T. T. P.; KATO, T. Takaak. Measuring the effect of environmental education for sustainable development at elementary schools: A case study in Da Nang city,Vietnam. Sustainable Environment Research 2016.

JACOBI, P. Educação Ambiental: o desafio da construção de um pensamento crítico, complexo, reflexivo. Educação e Pesquisa, v. 31, n. 2, p. 233-250, 2005.

LIMA, W. Aprendizagem e classificação social: um desafio aos conceitos. Fórum Crítico da Educação: Revista do ISEP/Programa de Mestrado em Ciências Pedagógicas. v. 3, n. 1, out. 2004.

LIMA, G. F. C.; LAYRARGUES, P. P.2014. Educar em Revista, Curitiba, Brasil, Edição Especial. DOI: 10.1590/0104-4060.38108.

MARPICA, N. S; MONTAGNINI, A. J.M. Panorama das Pesquisas Sobre Livros Didático e Educação Ambiental. Ciência \& Educação, v. 16, n. 1, p. 115-130, 2010

MENDONÇA FILHO, J.; TOMAZELLO, M. G. C. As imagens de ecossistemas em livros didáticos de ciências do ensino fundamental e suas implicações para a educação ambiental. Revista Eletrônica do Mestrado em Educação Ambiental, Porto Alegre, v. 9, p. 152-158, 2002. 
RIBEIRO, M. W. Os conteúdos ambientais em livros didáticos de geografia de $1^{\circ}$ e $2^{\circ}$ ciclos no ensino fundamental. 2006. 125 f. Dissertação (Mestrado em Educação) - Faculdade de Educação, Universidade Federal do Paraná, Curitiba, 2006.

RIZZO, R. M. Ser Sensível aos 3 R's - Reutilizar, Reciclar e Reduzir. Ambiente Brasil. 05 de junho de 2007. Disponível em: <http://noticias.ambientebrasil.com.br/artigos/2007/06/05/31467-ser-sensivel-aos-3-rsreutilizavel-retornavel-e-reciclavel.html> . Acesso em: 04/06/13.

RODRIGUES, S. J. A vida como bem maior: um desafio para a educação ambiental. Universidad de Havana, Cuba, 2001.

RODRIGUES, J. Environmental Education: A Propose of High School Stélio. 5th World Conference Educational Sciences - WCES, 2013. doi: 10.1016/j.sbspro.2014.01.199.

SANTOS, T. C.; COSTA, M. A. A Educação Ambiental nos Parâmetros Curriculares Nacionais. Atas do IX Encontro Nacional de Pesquisa em Educação em Ciências - IX ENPEC Águas de Lindóia, SP, 2013.

Secretaria de Educação Fundamental. Parâmetros curriculares nacionais: introdução aos parâmetros curriculares nacionais / Secretaria de Educação Fundamental. - Brasília: MEC/SEF, 1997. 126p. Disponível em: < http://portal.mec.gov.br/seb/arquivos/pdf/livro01.pdf> . Acesso em: 04/05/2013.

SILVA, S. P. O Espaço Dado à Educação Ambiental nos Livros Didáticos e as Mudanças Didáticas no Ensino de Ciências: Perspectivas Inovadoras Rumo ao Desenvolvimento da Reflexão Socioambiental e da Consciência Ecológico-Preventiva. 2011. Disponível em: <http://www.partes.com.br/educacao/artigos/ eaemensinodeciencias.asp $>$. Acesso em: 24/06/13.

SOARES, A. A. R; NOVICKI, V. Educação Ambiental Através de Livros Didáticos de História do Segundo Segmento do Ensino Fundamental. GT: Educação Ambiental / n. 22. Agência Financiadora: CAPES

SULEIMAN, M; ZANCUL, M. C. S. Meio Ambiente no Ensino de Ciências: Análise de Livros Didáticos Para os Anos Finais do Ensino Fundamental 1. Rev. eletrônica Mestr. Educ. Ambient. ISSN 1517-1256, v. 28, janeiro a junho de 2012.

Violante, A. C.; Silva, A. J. Decrescimento econômico: um ensaio crítico. Revista ADMpg Gestão Estratégica, v. 3, n. 1, p. 19-28, 2010. 